\title{
Qualitative Research Method - Phenomenology
}

\author{
Shahid N Khan ${ }^{1}$ \\ ${ }^{1}$ Department of Management, Monash University, Australia \\ Correspondence: Shahid N Khan, Department of Management, Monash University, Australia. E-mail: \\ shahid.khan@monash.edu
}

Received: August 20, 2014 Accepted: September 19, 2014 Online Published: October 30, 2014

doi:10.5539/ass.v10n21p298

URL: http://dx.doi.org/10.5539/ass.v10n21p298

\begin{abstract}
The researcher in this paper sought to identify the basic components that are integral part of any research methods while conducting a qualitative research. The researcher developed a qualitative research methods chapter while conducting research on a phenomenon of abusive supervision. This paper will help the research students to analyse a phenomenon such as abusive supervision in context of its ontology, epistemology, theoretical perspective, methodology and methods. Furthermore, target population, sampling technique, data collection methods and the role of a researcher in this whole research process, and another essential part of a qualitative research, ethics which play a crucial role while conducting and gathering a qualitative data, have also been discussed in detail.
\end{abstract}

Keywords: abusive supervision, phenomenology, ontology, epistemology, methodology

\section{Introduction}

The focus of this research is the employee's experience of abusive supervision. Prior research on abusive supervision sought to demonstrate that work to date in the field is dominated by a managerial and conceptual approach that privileges an examination of abusive supervision in terms of its effects for the organisation such as impact upon productivity, job tension, emotional exhaustion and turnover intentions, etc. (Harvey, Stoner, Hochwarter, \& Kacmar, 2007; Khan, Qureshi, \& Ahmad, 2010). There is a limited exploration of what abusive supervision means in terms of its aspects and features, what supervisory impulsive and strategic abuse means for employees, employers, peers, (Ferris et al., 2007; Tepper, Duffy, \& Breaux-Siognet, 2012). More specifically, the employees' own understandings and perceptions of the issue are marginalised in the literature. As with much of the work in the management academy, this field is dominated by quantitative and positivist approaches which downplay individual experiences and local and personal understandings in favour of broad-brush, numerical aggregates of data. The present research seeks to remedy this neglect by foregrounding an examination of employees' own perceptions and understandings of supervisory abuse in terms of its different features and aspects, e.g., supervisory impulsive and strategic abuse. What are its impacts on employees' morale and employees' responses to these impacts within an organisation in a cross-cultural context?

In order to achieve this purpose, the research seeks to answer these research questions.

1. Which features/aspects of abusive supervision in the workplace impact on employee's morale?

2. What are these impacts on employee morale in a cross-cultural context?

3. How do subordinates respond to different aspects/features of abusive supervision in a cross-cultural context?

As the present study is focusing on perceptions and understandings of supervisory abuse from employees' own experiences, it leads itself to a qualitative, interpretivist approach - one carried out through interviews as the primary method of data collection. This paper discussed the reasons for selecting a qualitative approach for the present study, the rationale for selecting an interpretive approach within a qualitative method, and the data collection method. At the end, ethical issues raised by the study have also been discussed and a path forward proposed.

\section{Research Paradigm}

Qualitative research may be located in any one of three paradigms, positivist, interpretivist, and critical (Denzin \& Lincoln, 2003; Punch, 1998). A paradigm is a structure or a set of suppositions and ideas that provides a pathway to see what the world looks like when its scientific aspect is related to its assumptions. It also provides 
questions and puzzles to be revealed and interpreted and indicates the research methods to be used (Neuman, 2011). Guba and Lincoln (1994, p. 107) defined a paradigm as 'a set of basic beliefs (or metaphysics) that deals with ultimates or first principles'. Patton (1990) argued that it is a view or perception regarding the complex phenomenon of the real world.

Kuhn (1970) is famous for being the first researcher to use paradigms in the context of a framework to understand inquiry. He sees paradigms as established rules and techniques, discovered by a scientific community, that help to identify and illuminate a problem and further give some reasonable direction to solve it and provide results and justifications that are acceptable to the scientific community for further reference.

The differences between a positivist and an interpretivist paradigm are shown below in table 1.1

Table 1. Differences between paradigms

\begin{tabular}{|c|c|c|}
\hline Positivism & Paradigm & Interpretivism \\
\hline Reality is independent of human perception. & Ontology & $\begin{array}{l}\text { Multiple realities and multiple truths/reality are } \\
\text { socially constructed and constantly changing. } \\
\text { Researcher and object are interactively }\end{array}$ \\
\hline $\begin{array}{c}\text { Investigator and investigated are independent } \\
\text { entities. }\end{array}$ & Epistemology & $\begin{array}{l}\text { linked/findings are mutually created within the } \\
\text { context of the situation which shapes the } \\
\text { inquiry. }\end{array}$ \\
\hline Quantitative & Method & Qualitative \\
\hline $\begin{array}{c}\text { To measure and analyse causal relationships } \\
\text { between variables within a value-free } \\
\text { framework. }\end{array}$ & Goal & Stress is on process and meaning. \\
\hline $\begin{array}{l}\text { Randomizations, blinding, highly structured } \\
\text { protocols, and written or orally administered } \\
\text { questionnaires with a limited range of } \\
\text { predetermined responses. }\end{array}$ & Techniques & $\begin{array}{l}\text { In depth and focus group interviews and } \\
\text { participants observation. }\end{array}$ \\
\hline $\begin{array}{l}\text { Larger than qualitative } \\
\text { sample/representative. }\end{array}$ & Sample Size & $\begin{array}{l}\text { Small/purposeful/respondents with important } \\
\text { information/not meant to be representative. }\end{array}$ \\
\hline
\end{tabular}

Source: Retrieved from (Sale, Lohfeld, \& Brazil, 2002, pp. 44-45).

Neuman (2011) differentiated interpretivism and positivism philosophical paradigms. He mentioned that the positivist view of the world is objective where behaviour and cause and effect can be measured and human activity can be predicted. He is more focused on the mechanisms of the world scientifically, and concentrated on calculation and estimation of the occurrence of events in the world. While an interpretivist view of the world allows for subjective values, where individuals are understood to form their own reality of the world in different contexts through interactions with others, in an interpretivist paradigm the researchers have no direct access to the real world (Carson, Gilmore, Perry, \& Gronhaug, 2001). Individuals are understood to perceive the world differently because of their own experiences and perceptions in different contexts. Each philosophical paradigm has its own strengths and weaknesses (Cavana, Delahaye, \& Sekaran, 2001). The most important things in considering methods for inquiry are the research requirements and research objectives (Cassell \& Johnson, 2006; Cavana et al., 2001).

As the researcher mentioned in the foregoing section, selection of the right paradigm will enable the researcher to answer present research questions from different perspectives, rather than from a single perspective. This will assist and authenticate the present research findings and provide an assurance that the existence of a single reality about supervisory abuse is not valid, it is always multiple one. Therefore, the researcher, after extensive consideration, chose an interpretivism rather than a positivism, as it is more suitable and comprehensive in illuminating the present research interest and further, will enable the researcher to listen to employees' 'hidden voices' about the phenomenon of abusive supervision in terms of its aspects and features, impacts, and the employees' responses to these impacts at work. These paradigms are further based on elements of ontology, epistemology, theoretical perspective, methodology and methods (Denzin \& Lincoln, 2003; Punch, 1998). 


\subsection{Ontology: Relativism}

Ontology is concerned with the nature of reality. Reality is perceived as subjective and depends upon how researchers and participants perceive it (Creswell, 2007; Punch, 1998). It is all about understanding the real world and its existence and action (Guba \& Lincoln, 1994).

In keeping with these ideas, it is argued that the present research is going to observe the phenomenon of abusive supervision from the employees' own experiences and understandings. Therefore, this research will focus on ontological questions which will dig-out the nature and reality of abusive supervision at work and reveal that abusive supervision is vicarious (Harris, Harvey, Harris, \& Cast, 2013) or real. Therefore, to answer the ontological perspective of the research questions, the present research will focus on: 'What are the employee's own experiences and understandings of supervisory abuse?' 'How does it impact an employee's morale? 'How do employees' respond these impacts at work?'

\subsection{Epistemology: Subjectivism}

Epistemology is concerned with the way knowledge is acquired. It depends upon the relationship between researcher and researched, and how the researchers perceive that reality (Creswell, 2007; Punch, 1998). Epistemology is the relationship between the researcher and the reality, and how this phenomenon of reality can be explored or known (Carson et al., 2001). In the literature, different types of epistemologies have been introduced, but the selection of epistemology for specific research is totally dependent upon the nature and the reality of the research (ontology). In this regard, Guba and Lincoln (1994) have identified two types of epistemologies; one is objectivist epistemology stating that the discovered and known reality is real and factual, and the second is subjectivist epistemology stating that the reality is created and discovered.

For the present research, the researcher is following the Guba and Lincoln (1994) subjectivist epistemology, as the purpose of the present research is to gain deeper understanding of the phenomenon of supervisory abuse in terms of its features and aspects through the employees' own experiences and understandings at work. How do they perceive it? How does it impact them? And how do they respond to the impacts of abusive supervision?

\subsection{Research Methodology}

Methodology is concerned with the process and the method by which the researcher acquires knowledge about the world (Creswell, 2007; Edwards \& Skinners, 2009; Punch, 1998) that may be helpful in answering the research questions and objectives of the present study. Research methodology helps the researcher to get data through multiple sources, e.g., questionnaires, face-to-face interviews, focus group interviews etc. It is argued that methodology plays a vital role in achieving research objectives. It points the research towards positivism/objectivism or interpretivism, according to the research objectives. If one of the research objectives is to supplement knowledge or fill an existing gap, then it would point towards positivism (quantitative methods). If the research objective is problem solving or exploring the phenomenon under study, then it would recommend interpretivism (qualitative methods) (Creswell, 2007). The following sections of this paper have shed light on components that have been selected for the present research. Further justification as to how and why these components for the present study have been selected, have also been discussed in detail.

\subsubsection{Research Purpose: Descriptive and Exploratory}

Exploratory research aims to highlight and explore an un-explored and un-interpreted phenomenon to better understand the problem (Cavana et al., 2001; Marshall \& Rossman, 2006). Further, exploratory research provides in-depth, rich data and descriptions. But sometimes exploratory research focuses on some unknown problems and tries to solve it in order to provide and identify a future research direction (Phillips \& Pugh, 2000).

As stated, the present research seeks to identify and explore abusive supervision especially in terms of its aspects and features from the employees' perspective in a cross-cultural context. This field is dominated by the positivist approach (Tepper, 2007) and the majority of the studies have been conducted to highlight its antecedents, consequences and factors of its occurrence of the broad term of abusive supervision. Therefore, it is argued that supervisory abuse needs to be explored by focusing upon employees' own experiences at work.

\subsubsection{Research Approach: Qualitative}

Qualitative research originates from the disciplines of education and social sciences with their studies of complex human behaviour (Taylor, 1984). According to Burns and Grove (2009) qualitative research is a systematic and subjective approach to highlight and explain daily life experiences and to further give them meaning. Qualitative research allows researchers to deeply explore behaviours, different perspectives, and life 
experiences to discover the complexities of the situation through an holistic framework (Holloway \& Wheeler, 2002). Creswell (2007, p. 15) defined qualitative research this way:

\begin{abstract}
'Qualitative research is an inquiry process of understanding based on distinct methodological traditions on inquiry that explore a social or human problem. The researcher builds a complex, holistic picture, analyses words, reports details of informants, and conducts the study in a natural setting'.
\end{abstract}

While this approach is further explained by McLeod (2001) who posits that it is very difficult and challenging to understand the human world scientifically, but we can work out the truth that will help us to find solutions. This study explored and illuminated supervisory abuse, its impacts and employees' responses to these impacts from employees' own understandings and experiences in the cross-cultural context of Australian and Pakistani cultural settings. The methodological framework is qualitative in nature. Qualitative research is used to explore the potential antecedents and factors about which little has been known and explored (Strauss \& Corbin, 1998). Qualitative research is an interpretive and naturalistic approach (Guba \& Lincoln, 1994), which is based upon the observations and interpretations of people's perceptions of different events (Guba \& Lincoln, 1994; Neuman, 2011).

As this study is, about the neglected and marginalised aspects of employees' own understandings and experiences of the phenomenon of abusive supervision, therefore a qualitative approach is most appropriate for this study. The nature of the research questions provides a solid base for conducting the present study with a qualitative approach as in a qualitative study we can explore and illuminate the phenomenon, mainly focusing on 'what?' and 'how?' types of questions. Identification of variables is not an easy task; and must be explored to provide a broad view of the topic under study. One reason for conducting this study via a qualitative approach was to present a detailed view of the topic from the perspective of employees who have been subjected to abusive supervision, and their perceptions and understandings about it in naturel settings such as face-to-face interviews and observations. Extensive data collection, from multiple sources, is the back bone of any qualitative study. In this context, the focus of the present study is upon developing a descriptive and explanatory type of theory. For this reason, the researcher have collected data through multiple avenues such as face-to-face interviews, texts, etc., which is why the researcher chooses a qualitative approach to conduct the present research.

\title{
2.3.3 Research Strategy: Interpretive Type of Interviews
}

Ultimately, the present research is based upon an interpretive approach because the researcher is trying to see the social world from the participant's perspective and consider the participant's perception of the world (Edwards \& Skinners, 2009). It is further explained by Denzin and Lincoln (2003) that an interpretive approach depends upon both the participant's view and the researcher's view of reality, so that the researcher can discover the significance and importance of an action or make it understandable and clear for others what this specific action means. It needs to be interpreted and deduced in a way that other people can easily understand. People create their own worlds of reality while interacting with the outer world around them. They assign meaning to the world around them, and to understand that meaning the researcher has to approach them while interpreting their assigned meaning (Orlikowski \& Baroudi, 1991).

In this regard, the researcher has selected an interpretive approach which is most suitable for collecting data within an interpretive paradigm; therefore the researcher has not design a new qualitative method but rather conducted semi-structured interviews for the present study. Analysis and interpretation are the factors that played a crucial role and authenticated the results of this study. Moreover, rich and in-depth data can play a crucial in understanding the phenomenon under study and explain and resolve the research questions. Further, it is argued that supervisory abuse, in terms of its aspects and features which are the subdomain of abusive supervision, lacks formal propositions, quantifiable measures of variables, and testing of hypotheses. This also supports conducting this study with an interpretive approach.

\subsubsection{Preference of Interpretive Approach over Narrative Approach}

A narrative approach is used to explore the lives of individuals specifically focusing on the events that have occurred in their lives. Czarniawska-Joerges $(2004$, p. 7) defined it as an approach which is understood as a spoken or written text giving an account of an event/action or series of actions/events, chronologically connected'. In this type of study, the interviewer motivates the interviewee to tell the story (of the area of interest) linking all the story events chronologically (Uwe Flick, 2002).

Therefore, it is argued that the present research is not considering a narrative approach as it is to explore a single phenomenon, not the individual's lives. The second reason for not considering a narrative approach for the 
present study is that the narrative approach focuses on the chronological order of the story events, while in the present research chronological order does not add value.

\section{Target Population}

Traditional management structure consists of three levels: Senior management, middle management and first-line management (Cole, 1998). First-line managers or supervisors play the role of bridge between management and the non-management workforce and workers (Hales, 2005; Lennox, 2012).

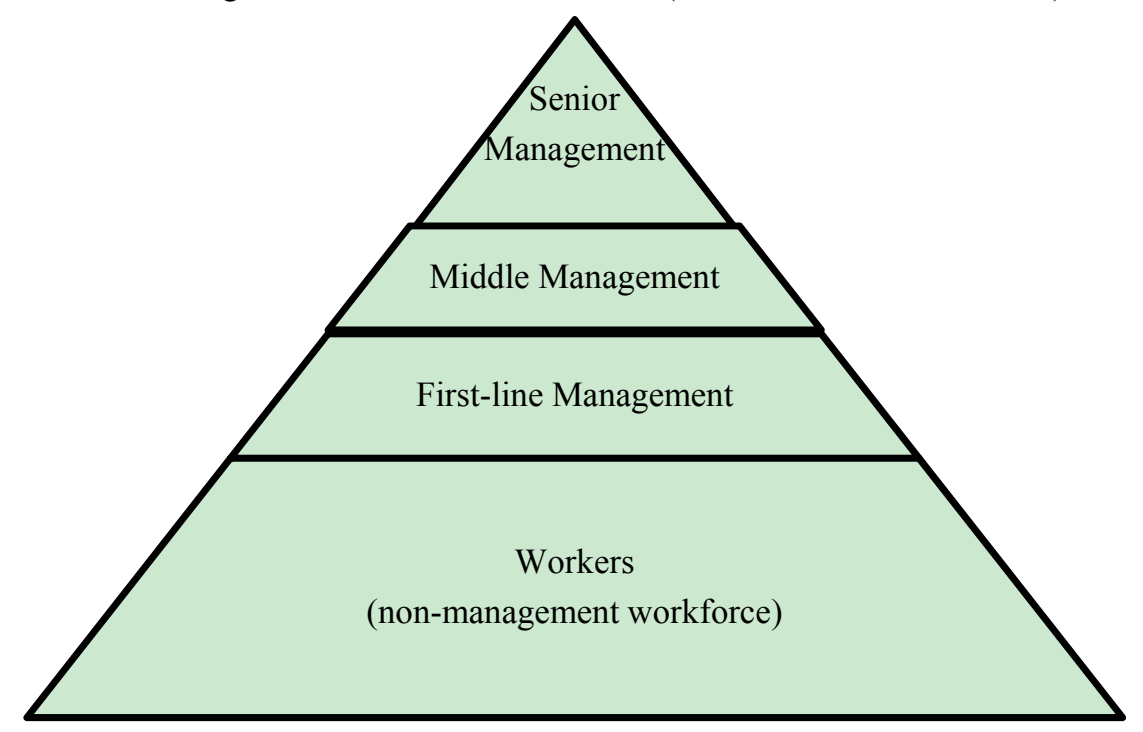

Figure 1. Traditional pyramids of management levels Source: Adopted from Cole (1998, p. 19)

First-line managers have different titles - supervisors, superintendents, team leaders, group leaders, foremen/forewomen, coaches, facilitators, section managers, leading hands, coordinators or area managers (Cole, 1998; Gilmour \& Lansbury, 1979; Hales, 2005; Leonard \& Holgert, 2004). According to a survey conducted by the National Institute of Industrial Psychology in Britain, more than 200 relevant titles for 'supervisory' positions have been identified, while the Swedish Council for Personnel Administration reported a dozen translations of the title 'supervisor' (Gilmour \& Lansbury, 1979). Hence, all these terms are used interchangeably in different organisations, countries and cultures. The reasons for selecting a non-management workforce as a target population for the present study are based on their direct interaction with their immediate supervisors who directly exhibit their behaviour towards their subordinates.

\subsection{Individual (Age, Gender, and Tenure)}

To highlight the importance of subordinates' age, gender and tenure to the supervisor, the researcher has identified few studies conducted in this domain. Tepper (2000), in developing the most authentic 15-item scale of abusive supervision, used employees from six different public and private sectors organisations. He selected only full-time employees who were in a relationship with their supervisors for six months at the time of data collection. Forty-three percent of the subordinates were female, and thirty-five percent of the subordinates had female supervisors. While subordinates' age range was $35-39$ years and the supervisors' age range was $40-44$ years. Tepper, Duffy, Henle, and Lambert (2006) conducted another study on National Guard members and their military supervisors. They included all departments, e.g., engineering, administration, machine repair, technical and non-technical training, etc. Ninety-three percent subordinates were male, and ninety-six percent of supervisors were male. Subordinates' age range was $25-29$ years, and supervisors' age range was $30-39$ years. The tenure with the supervisor ranged from six months to over five years while the average tenure with a supervisor was recorded at 2.45 years. They found that tenure with a supervisor had no effect on the result.

Tepper et al. (2009) conducted two studies of supervised employees. In the first study, the three samples consisted of men $57 \%, 35 \%$, and $65 \%$ respectively with average ages of 27,40 , and 43 years. In the second study, $65 \%$ of participants were female and their average age was 45 years. Tenure with supervisor was a maximum of 11 years, and a minimum less than one year. The data collected from public-and-private-sector employees in education, services industries, manufacturing and retail, and small businesses respectively. Zellars, Tepper, and Duffy (2002) conducted a study in which ninety-three percent of subordinates were male and ninety-six percent 
of supervisors were male and their tenure with the supervisor was a minimum of less than one year and a maximum of over twenty years. The study by Tepper, Moss, and Duffy (2011) was based on participants from seven health-sector organisations including hospitals, long-term care facilities, and out-patient facilities. They contacted the participants by e-mail, announcements at staff meetings, and/or distribution of flyers. The supervisors' average age was forty-six years and sixty-nine percent were women. All were from diverse ethnic groups including black, while, Hispanic, and Asian etc. Twenty-one percent were from lower-level supervisory positions. The subordinates' average age was forty-four years and seventy-seven percent were women. They were drawn from the same ethnic groups as were the supervisors. Their average tenure with a supervisor was 4.33 years.

As far as the subordinate's tenure with the abusive supervisor is concerned, it is argued that the characteristics of abusive supervision includes a sustained and enduring relationship with the subordinate until and unless the (1) the target terminates the relationship, (2) the agent (The supervisor) terminates the relationship, or (3) the agent modifies his/her behaviour (Jezl, Molidor, \& Wright, 1996; Shepard \& Campbell, 1992). In all of the above-mentioned studies, it is evident that a subordinate's tenure with a supervisor varies from study to study and has been reported as a minimum of six months (Baillien, Neyens, De Witte, \& De Cuyper, 2009; Einarsen, Raknes, \& Matthiesen, 1994; Leymann, 1996; Thau, Bennett, Mitchell, \& Marrs, 2009) while Tepper et al. (2006) have reported in their study that it has no significant effects on abusive supervision results.

But contrary to existing literature, the researcher has selected all those employees who have faced abusive supervision, irrespective of the duration during which they were exposed to abusive supervision, as the researcher has explored their personal experiences regarding abusive supervision that may vary from employee to employee. The second reason for not specifying six-month minimum for selecting employees for interview was to avoid the difficulties in and barriers to approaching the participants, as the present study has adopted a qualitative approach and used a snow-ball sampling technique to reach the target population.

As for as the age and gender are concerned, Feshbach (1997) has argued that intensity of aggression and hostility exists more in males than females. Contrary to this argument, Einarsen et al. (1994) have linked the intensity of abusive supervision towards subordinates with the frequency of interaction between supervisors and subordinates. They also reported a high intensity of bullying behaviour towards administrative staff due to their daily interaction with their supervisors and a low intensity for teachers, as they work independently and have very minor interaction with their supervisors. Hofstede, Hofstede, and Minkov (2010) have focused upon attitudes and values rather than the individual's position, age, gender etc. In keeping with Hofstede's approach, the researcher has interviewed subordinates irrespective of their age and gender, chose subordinates who had experience the phenomenon of abusive supervision.

\subsection{Organisational (Task-oriented, Competitive Work Environments, Centralised Decision Making System)}

An organisation's decision making style plays an important role in organisational success and development and all organisations in industry vary in their decision making styles. Drucker (1954) identified routine and strategic decision making styles while Simon (1960) identified programmed and non-programmed decision making styles. Simon (1973, p. 270) defined decision-making as 'the central activity in which the organisation is engaged'. A paradigm of the decision making process has been developed by Huber and McDaniel (1986) who argued that the most important aspects, when designing an organisation, are the structures and processes that support the organisational decision making process. They further argued that hostile, complex and turbulent work environments support the use of a decision-making paradigm.

The decision-making style within an organisation affects individuals positively or negatively, especially in their growth and development (Price, 1973). This line of reasoning produces what Huber and McDaniel (1986) refer to as 'central activity' in that decision making is linked with an organisation's strategic management level where decision making is considered and focused upon as the central activity. This is what Drucker (1954) referred to as strategic decision-making style. Organisations delegate these decisions-making responsibilities to organisational members or a group of members who are called 'decision units'. The creation of decision units within an organisation is a step towards a decentralised decision making-style where the authority of decision making is diffused (Huber \& McDaniel, 1986). Employees who face decentralised team leadership have considerable advantages over the employees with centralized team leadership (Pearce, 2009).

But contrary to the above mentioned literature, it is argued that the focus of the present study is exploration and identification of the phenomenon of abusive supervision in terms of its aspects and features, its impacts on employees' morale and furthers the employees' individual responses to these impacts in a cross-cultural context. Therefore the focus of the present study is on employees' experiences and understandings of the phenomenon of 
abusive supervision, rather than upon organisational management style, e.g., centralised or decentralised, a task oriented or competitive work environment. The second reason for not considering organisational structure, etc., was that the researcher was not interested to conduct a cross-sectional study but a cross-cultural study. And the third reason for not considering the organisational structure was that the researcher did not wish to narrow down the target population as he planned to use snow-ball sampling, which could make it difficult, in fact impossible to obtain the type of defined data where the focus of the study was on comparison of abusive supervision in terms of organisation structure etc.

\subsection{Employment-Related Factors (Causal vs Full Time, Professional Vs Low-Skilled Employees)}

The effects of abusive supervision are more severe for employees who have less job mobility (Tepper, 2000). Tepper and colleagues further conducted a study in which they approached only full-time employees and their bosses (Tepper, 2000; Tepper, Duffy, Hoobler, \& Ensley, 2004; Tepper, Duffy, \& Shaw, 2001; Tepper, Moss, Lockhart, \& Carr, 2007) because the focus of their studies were on a cause-and-effects situation studying how abusive supervision affects employees' turnover intention, organisation citizenship behaviour and resistance to abusive supervision. The same type of study was conducted by Harvey et al. (2007) in which they recruited full-time employees, mostly professional and were in administrative positions, but again the focus of the study was on measuring the effects of abusive supervision on negative employee outcomes, e.g., job tension, emotional exhaustion and turnover intention.

In keeping with these ideas, it is worthwhile to mention that a majority of the studies which focused on employee's casual or full-time status were considering cause-and-effects situations and adopted a positivist and quantitative approach while, the present study has examined supervisory abuse from employees' own perspectives and understandings in a cross-cultural context adopting an interpretive qualitative approach. As Hofstede et al. (2010) argued while studying a phenomenon in a cross-cultural context, the most important thing is to consider the values and attitudes, rather than a subordinate's position, e.g., causal or full-time. The present study is about the subordinate's past experiences of abusive supervision. Whether they have faced abusive supervision as causal or full-time workers and whether they were low-skilled or professional employees of the organisation does not add value for the present study. Furthermore, the researcher has not involved the organisations or the supervisors while conducted interviews with subordinates because this study was based solely upon the perceptions and understandings of employees' own experiences regarding their supervisory abuse.

\section{Unit of Analysis}

The most important part of any research is the unit of analysis, as the entire research is based upon it. According to Neuman (2011, p. 69), the unit of analysis is: 'The units, cases, or parts of social life that are under consideration. They are key to developing concepts, empirically measuring or observing concepts, and using data analyses'. The unit of analysis could be individuals, dyads, groups, or organisations. The determination of the unit of analysis during the initial stage of research is crucial as the conceptual framework, data collection techniques and sample size all depends upon the unit of analysis (Cavana et al., 2001; Neuman, 2011).

For the present research, the unit of analysis was workers (non-management workforce). The researcher has applied a snow-ball sampling technique to workers from both public and private sector organisations (Tepper, 2000; Tepper et al., 2001) from Australia and Pakistan. In-depth interviews have been conducted with employees to get their perceptions of what aspects and features of abusive supervision have impacted on their morale, and what were their responses to these impacts. As the researcher, has previously mentioned that 'supervision' means superintendents, team leaders, group leaders, foremen/forewomen, coaches, facilitators, section managers, leading hands, coordinators or area managers (Cole, 1998; Gilmour \& Lansbury, 1979; Hales, 2005; Leonard \& Holgert, 2004). All these terms are used interchangeably in different organisations, countries and cultures.

\section{Population and Sample}

The target population of the present study was workers (the non-management workforce), especially those workers who have experienced the phenomenon of abusive supervision at work. 'Level of supervision', which the researcher already has mentioned, means first-line managers (Cole, 1998; Gilmour \& Lansbury, 1979; Hales, 2005; Leonard \& Holgert, 2004). As mentioned earlier that abusive supervision is a subjective assessment, as some workers may perceive their supervisors to be abusive and some may not. It varies from worker to worker. In short, the target population of the present study was workers/employees who have faced abusive supervision at work. 
The reason for selecting abused employees as a target population for the present study was that abusive supervision has adverse effects on an abused employee's performance, attitude, self-respect, physical health, job satisfaction, life satisfaction, organisational commitment, job tension, emotional exhaustion, turnover intention and actual turnover, absenteeism, conflict between work and family-life and psychological distress (Breaux, Perrewé, Hall, Frink, \& Hochwarter, 2008; Burris, Detert, \& Chiaburu, 2008; Carlson, Ferguson, Hunter, \& Whitten, 2012; Khan et al., 2010; Tepper, 2000, 2007; Tepper et al., 2009; Tepper et al., 2006; Tepper et al., 2004; Zellars et al., 2002). This costs the organisation in terms of lost performance, lost productivity, employee turnover and increased health care expenditures (Tepper, 2007; Tepper et al., 2011). But the question here is this: why are these specific employees the target of supervisors' abusive behaviour? To identify the factors behind the occurrence of abusive behaviour towards specific employees, Olweus (1978) argued that it is due to employees' perceived lower performance; they fit a provocative victim profile, and according to this profile it is difficult and annoying to work with them. This argument is also supported by Tepper et al. (2011). Tepper and colleagues further argued that abusive supervision is a costly phenomenon in terms of lost productivity, absenteeism, turnover, and health care expenditures. That's why present study has focused upon identifying the features and aspects, of abusive supervision as different aspects and features might have different effects on employees' morale and they might respond them differently. These abused employees being a source of getting and sustaining a competitive advantage for the firm, can affect the firm's performance in the market place and industry. Those employees not abused at work by the same supervisor, were beyond the scope of the present study as this does not have adverse effects on an organisation's performance and productivity.

Abused employees from both public and private sector organisations in a cross-cultural context, i.e., Australia and Pakistan, have been approached to participate in the present study, as the purpose of the present study was to identify and explore the aspects and features of abusive supervision from an employee's perspective. Hence, the first criterion for participant selection was 'employees who have faced or suffered from abusive supervision at work'. A second criterion was that Australian-or-Pakistani-born participants have been recruited for the present study as the researcher was going to compare employees' own experience of abusive supervision in a cross-cultural context. Participants from these countries have illuminated cultural differences.

Sampling is a method of deducing information about a whole population from a limited number of units. Only appropriate and proper development of the sampling technique will lead to authenticity of results. The importance of sampling in any type of research is highlighted by Punch (1998, p. 193): 'We cannot study everyone, everywhere doing everything. Sampling decisions are required not only about which people to interview or which events to observe, but also about settings and processes.' Sampling is closely linked to the purpose and research questions of the study. These questions lead to selection of samples from a large pool which further generalises results to the population (Neuman, 2011).

For the present research, the researcher has adopted 'purposeful sampling'. It is a good technique to deeply investigate, discover and understand the phenomenon under study through a sample which gives detailed information (Merriam, 2002). Ideally, the sample represents the whole population on the characteristics of interest (Burns \& Grove, 2009). As the researcher has adopted purposeful sampling, the selected individuals has been informed regarding the research problem and rationale for the study (Creswell, 2007). Purposeful sampling is further divided into three main types: judgement sampling, in which the researcher selects only those participants who can answer the research questions; snow-ball sampling where the researcher selects only potential participants for the research; and quota sampling, based on a quota from each representative group (Cavana et al., 2001).

For this present study, the researcher has selected the snow-ball sampling technique (Loh, Calleja, \& Restubog, 2011). This is a useful technique for reaching potential participants. As the topic of the present research is very sensitive, employees could be reluctant to talk about their supervisors' abusive behaviour. The researcher has used his personal contacts and social network to reach employees to talk about their experience of supervision generally and then, if the data already produced in the academic field are correct, many of these people will have had less-than-positive experiences that the researcher can go on to explore further. A snow-ball technique has been used to get more contacts for data collection through interviews. This technique works like a chain to reach the potential participants.

The size of the sample is determined by the type of research we are going to conduct, whether it is quantitative or qualitative research. Researchers have defined different criteria for quantitative and qualitative research, but the common thing is that the criteria depend upon population characteristics, types of data and its accuracy likes its degree of confidence. It is representativeness that matters, not whether the sample is small or large (Neuman, 
2011). Relevance is even more important than representativeness in directing the study toward the participant selection ( Flick, 2009).

For the present study, the researcher has conducted thirty interviews of employees each in Australia and Pakistan. Hence the overall sample size was sixty face-to-face, semi-structured, in-depth interviews. Creswell (2007) emphasised that even a sample of ten can represent a reasonable size, as the most important thing in a qualitative research is the quality not the quantity. Sixty participants were merely an estimation of the sample size. The researcher could continue to conduct interviews until and unless data saturation occured and new data ceased to emerge from interviews (Arnault, 2002; Strauss, 1987; Strauss \& Corbin, 1998).

\section{Interviews}

The type of interviews includes structured, semi-structured, open-ended, face-to-face, telephonic, one-on-one, computer-assisted, group interviews, and focus group interviews, etc. An interview 'provides a unique opportunity to uncover rich and complex information from an individual' (Cavana et al., 2001, p. 138). Willis (2007) states that the environment and situation in which you are going to conduct your research play a crucial role in how you organise the conducting of interviews, your selection of interviewees, your questioning material, your structure for the interview and how you understand and interpret the data.

Thus the present research was totally based on employee interviews for data collection. In this regard, the researcher has approached the participants after office hours and has endeavoured to select a private location for the interviews on these Participants were assured of privacy and confidentiality of the interview material. Hence the participant were more relaxed and motivated to share his/her perceptions and experiences of abusive supervision at work, and such an environment has enabled the researcher to get more rich data and conduct an in-depth interview.

\section{Data Collection Procedures}

For data collection, the employees have been approached after office hours and have been given information regarding the nature and rationale of the research. The respondents have been guaranteed the anonymity of the data and results. As earlier mentioned the researcher was using an interpretive approach and adopted a snowball sampling technique. The participants in the study have been contacted and selected through personal contacts and social networking (Weaks, 2002). To identify and explore what aspects and features constitute abusive supervision, the researcher has conducted face-to-face, in-depth open-ended and semi-structured interviews. In this type of interviews, the researcher had a better chance to obtain from interviewees opinions, views, perceptions and experiences in detail. The nature of semi-structured interviews have allowed and enabled the researcher to prepare a topic guide or relevant questions to be covered with each participant in one sitting (Polit $\&$ Beck, 2008). Further, face-to-face interviews have allowed the researcher to clarify any ambiguities and important points. The interviews were planned to last sixty to ninety minutes.

The interviews were audio-taped (with permission from the participant) so as to preserve an accurate account of the interview which could be replayed for analytic purposes. Anonymity has been assured during the course of recording. Participants have been reminded of their right to withdraw from the study or terminate the interview at any time before commencing the session.

\section{Ethical Issues}

'Ethics begins and ends with you, the researcher'

(Neuman, 2011, p. 143)

Ethical issues are important for both quantitative and qualitative research, but ethical considerations are more important in qualitative research as qualitative research approaches often intrudes in participant's lives (Punch, 1998). That's why Neuman (2011, p. 143) made the individual researcher responsible for research ethics. He added that 'It is the moral and professional obligation of the individual researcher to be ethical even when research participants are unaware of or unconcerned about ethics'.

In the whole research process, the researcher is the one who knows the potential benefits and losses involved in an on-going research project. While collecting any kind of information or data from participants, the researcher should disclose all benefits and losses that may affect the participants (Punch, 1998). Some general ethical issues in research that result in some prohibitions are: never cause unnecessary or irreversible harm to participants, secure prior voluntary consent when possible and never unnecessarily humiliate, degrade, or release harmful information about specific individuals that was collected for research purposes. These are minimal standards and are subject to interpretation (e.g., what does 'unnecessary' mean in a specific situation?). Participation in any 
kind of research must be voluntary, and the researcher must inform participants regarding all aspects of research studies. In this regard, this is pertinent to note that the researcher have got an informed consent statement signed by the participants, inform them of their rights and provide brief information about the research study (Neuman, 2011).

To avoid the organisation's involvement in data collection, from the ethics approval perspective, the researcher has not recruited participants through their organisations. Rather, individuals have been contacted, using a snow-ball technique, through the researcher's personal contacts and social networks. To get the full essence of the study, the researcher have got the participant's confidence, consent and approval before proceeding in an interview with the participant. Before approaching participants for data collection through interviews, prior informed consent have also been obtained from them and they had been informed that they can withdraw anytime during the interview. To avoid any kind of identification of individuals, supervisors or organisations, the present study was based on employees' past experiences and perceptions of the phenomenon of abusive supervision. Participants have been motivated to share their experiences of abusive supervision but not the specific individual supervisors or organisations. If advertently or inadvertently the participants had identified any individual supervisors or organisation, the researcher have immediately reminded them that the researcher did not wished them to disclose such information. And while transcribing the audio recordings any individual supervisors and organisation identification have been replaced with pseudonyms or omitted altogether. And at the end of the interview, the researcher has assured the interviewee of the confidentiality of interviewed data. Given the potentially sensitive nature of the topic for employees and the fact that the researcher would be discussing issues that may raise some painful memories for the participants, the researcher would have identified support or other information services that individuals might access in their area should they feel the need to after our conversation, and would have provided these details to each participant.

After data collection, all the data in any form, e.g., printed transcripts or audio recordings, have been kept in a locked filing cabinet in the researcher's office and any electronic data (NVivo) files have been stored in password-protected computers.

\section{Summary/Conclusion}

In this paper, the researcher has highlighted the reasons behind the selection of a qualitative approach instead of a quantitative approach and further reasons for a phenomenological approach. Its prefer-ability over other qualitative approaches has also been highlighted and linked with the present research. Qualitative data collection methods and in-depth interviews have briefly been discussed and ethical issues related to this study have also been explained.

\section{References}

Arnault, D. S. (2002). Help-Seeking and Social Support in Japanese Sojourners. Western Journal of Nursing Research, 24(3), 295-306. http://dx.doi.org/10.1177/01939450222045914

Baillien, E., Neyens, I., De Witte, H., \& De Cuyper, N. (2009). A qualitative study on the development of workplace bullying: Towards a three way model. Journal of Community \& Applied Social Psychology, 19(1), 1-16. http://dx.doi.org/10.1002/casp.977

Breaux, D. M., Perrewé, P. L., Hall, A. T., Frink, D. D., \& Hochwarter, W. A. (2008). Time to Try a Little Tenderness? The Detrimental Effects of Accountability When Coupled With Abusive Supervision. Journal of Leadership \& Organizational Studies, 15(2), 111-122. http://dx.doi.org/10.1177/1548051808321787

Burns, N., \& Grove, S. K. (2009). The Practice of Nursing Research: Appraisal, Synthesis, and Generation of Evidence: Saunders/Elsevier.

Burris, E. R., Detert, J. R., \& Chiaburu, D. S. (2008). Quitting Before Leaving: The Mediating Effects of Psychological Attachment and Detachment on Voice. Journal of Applied Psychology, 93(4), 912-922. http://dx.doi.org/10.1037/0021-9010.93.4.912

Carlson, D., Ferguson, M., Hunter, E., \& Whitten, D. (2012). Abusive supervision and work-family conflict: The path through emotional labor and burnout. The Leadership Quarterly, 23(5), 849-859. doi: http://dx.doi.org/10.1016/j.leaqua.2012.05.003 http://dx.doi.org/10.1016/j.leaqua.2012.05.003

Carson, D., Gilmore, A., Perry, C., \& Gronhaug, K. (2001). Qualitative Marketing Research

Cassell, C., \& Johnson, P. (2006). Action research: explaining the diversity. Human Relations, 59(6), 783-814. http://dx.doi.org/10.1177/0018726706067080

Cavana, R. Y., Delahaye, B. L., \& Sekaran, U. (2001). Applied Business Research: Qualitative and Quantitative 
Methods (1st ed.). US \& Australia: John Wiley \& Sons Australia, Ltd

Cole, K. (1998). Supervision: Management in Action. New York \& Sydney: Prentice Hall.

Creswell, J. W. (2007). Qualitative inquiry and research design: Choosing among five traditions.

Czarniawska-Joerges, B. (2004). Narratives in social science research: Sage Publications, Inc.

Denzin, K. N., \& Lincoln, S. Y. (2003). Introduction: The Discipline and Practice of Qualitative Research. In N. K. Denzin, \& Y. S. Lincoln, (Ed.), Qualitative Research (3rd ed., pp. 1-32). Thousands Oaks, CA: Sage.

Drucker, P. (1954). The Practice of Management. New York: Harper and Brothers.

Edwards, A., \& Skinners, J. (2009). Research Paradigms in Qualitative Sports Research Management. In A. E. J. Skinners (Ed.), Qualitative Reseaerch in Sports Management (1st ed., p. 439). UK \& USA: Elesiver Ltd.

Einarsen, S., Raknes, B. r. I., \& Matthiesen, S. B. (1994). Bullying and harassment at work and their relationships to work environment quality: An exploratory study. European journal of work and organizational psychology, 4(4), 381-401. http://dx.doi.org/10.1080/13594329408410497

Ferris, Lance, D., Zinko, R., Brouer, R. L., Buckley, M. R., \& Harvey, M. G. (2007). Strategic bullying as a supplementary, balanced perspective on destructive leadership. The Leadership Quarterly, 18(3), 195-206. http://dx.doi.org/10.1016/j.leaqua.2007.03.004

Feshbach, S. (1997). The psychology of aggression: Insights and issues Aggression (pp. 213-235): Springer.

Flick, U. (2002). Qualitative research-state of the art. Social science information, 41(1), 5-24. http://dx.doi.org/10.1177/0539018402041001001

Flick, U. (2009). An Introduction to Qualitative Research (p. 505). Retrieved from $\mathrm{http} / /$ books.google.com.au/books?hl=en\&lr=\&id=sFv1oWX2DoEC\&oi=fnd\&pg=PR5\&dq=flick $+1998+$ an +introduction+to + qualitative + research\&ots $=$ oytWy_LdCM\&sig=rop1t17gajAT0z_tKmg5sABqxvA\#v=one page\&q=flick $\% 201998 \% 20$ an $\% 20$ introduction $\% 20$ to $\% 20$ qualitative $\% 20$ research $\& \mathrm{f}=$ false

Gilmour, P., \& Lansbury, R. D. (1979). Training the First Line Managers for New Organisational Careers: An Australian Study. Australian Journal of Management (University of New South Wales), 4(1), 55. http://dx.doi.org/10.1177/031289627900400104

Guba, E. G., \& Lincoln, Y. S. (1994). Competing paradigms in qualitative research. In N. K. D. Y. S. Lincoln (Ed.), Handbook of qualitative research (pp. 105-117). Thousand Oaks, CA: Sage.

Hales, C. (2005). Rooted in Supervision, Branching into Management: Continuity and Change in the Role of First-Line Manager. Journal of Management Studies, 42(3), 471-506. http://dx.doi.org/10.1111/j.1467-6486.2005.00506.x

Harris, K. J., Harvey, P., Harris, R. B., \& Cast, M. (2013). An Investigation of Abusive Supervision, Vicarious Abusive Supervision, and Their Joint Impacts. Journal of Social Psychology, 153(1), 38-50. http://dx.doi.org/10.1080/00224545.2012.703709

Harvey, P., Stoner, J., Hochwarter, W., \& Kacmar, C. (2007). Coping with abusive supervision: The neutralizing effects of ingratiation and positive affect on negative employee outcomes. The Leadership Quarterly, 18(3), 264-280. http://dx.doi.org/10.1016/j.leaqua.2007.03.008

Hofstede, G., Hofstede, J. G., \& Minkov, M. (2010). Cultures and Organizations: Software of the Mind: Intercultural cooperation and its importance for servival (3rd ed.). United States: McGraw Hill.

Holloway, I., \& Wheeler, S. (2002). Qualitative Research in Nursing (pp. 296).

Huber, G. P., \& McDaniel, R. R. (1986). The Decision-Making Paradigm of Organizational Design. Management Science, 32(5), 572-589. http://dx.doi.org/10.1287/mnsc.32.5.572

Jezl, D. R., Molidor, C. E., \& Wright, T. L. (1996). Physical, sexual and psychological abuse in high school dating relationships: Prevalence rates and self-esteem issues. Child and Adolescent Social Work Journal, 13(1), 69-87. http://dx.doi.org/10.1007/BF01876596

Khan, S. N., Qureshi, I. M., \& Ahmad, H. I. (2010). Abusive Supervision and Negative Employee Outcomes. European Journal of Social Sciences, 15(4), 490-500.

Kuhn, T. S. (1970). The Structure of scientific revolutions (2nd ed.). Chicago: University of Chicago Press.

Lennox, G. (2012). Coming into line. Training Journal, 36-39. 
Leonard, E. C., \& Holgert, R. L. (2004). Supervision: Concepts and Practices of Mangement $9 E$ (J. W. Challoun Ed.). USA: Thomson, South-Western.

Leymann, H. (1996). The content and development of mobbing at work. European Journal of Work and Organizational Psychology, 5(2), 165-184. http://dx.doi.org/10.1080/13594329608414853

Loh, J., Calleja, F., \& Restubog, S. L. D. (2011). Words that Hurt: A Qualitative Study of Parental Verbal Abuse in the Philippines. Journal of Interpersonal Violence, 26(11), 2244-2263. http://dx.doi.org/10.1177/ 0886260510383031

Marshall, C., \& Rossman, G. B. (2006). Designing Qualitative Research (p. 262).

McLeod, J. (2001). Qualitative Research in Counselling and Psychotherapy. [N.p.]: SAGE.

Merriam, S. B. (2002). Qualitative Research in Practice. Examples for Dis-cussion and Analysis (p. 439).

Neuman, W. L. (2011). Social Research Methods: Qualitative and Quantitative Approaches (D. Musslewhite Ed. 7th ed.). USA: Allyn and Bacon.

Olweus, D. (1978). Aggression in the schools: Bullies and whipping boys. Oxford England: Hemisphere.

Orlikowski, W. J., \& Baroudi, J. J. (1991). Studying information technology in organizations: Research approaches and assumptions. Information systems research, 2(1), 1-28. http://dx.doi.org/10.1287/isre.2.1.1

Patton, M. Q. (1990). Qualitative Evaluation and Research Methods (2nd ed.). Thousand Oaks, CA, USA: Sage Publications, Inc.

Pearce, C. L. M. C. C. S. J. H. P. (2009). Where Do We Go From Here?: Is Shared Leadership the Key to Team Success? Organizational Dynamics, 38(3), 234-238. http://dx.doi.org/10.1016/j.orgdyn.2009.04.008

Phillips, E. M., \& Pugh, D. S. (2000). How To Get a PhD: A Handbook for Students and Their Supervisors (3rd ed.).

Polit, F. D., \& Beck, T. C. (2008). In H. Surrena (Ed.), Nursing Research-Generating and Assessing Evidence for Nursing Practice (pp. 1-816). Retrieved from http://www.amazon.com/Nursing-ResearchGenerating-Assessing-Evidence/dp/1605477087\#reader_1605477087

Price, D. Z. (1973). Relationship of Decision Styles and Self-Actualization: Home Economics Research Journal.

Punch, K. F. (1998). Introduction to Social Research: Quantitative and Qualitative Approaches (1st ed.). London, Thousand Oaks California, New Delhi: SAGE Publications.

Sale, J. M., Lohfeld, L., \& Brazil, K. (2002). Revisiting the Quantitative-Qualitative Debate: Implications for Mixed-Methods Research. Quality and Quantity, 36(1), 43-53. http://dx.doi.org/10.1023/A:1014301607592

Shepard, M. F., \& Campbell, J. A. (1992). The abusive behavior inventory a measure of psychological and physical abuse. Journal of Interpersonal Violence, 7(3), 291-305. http://dx.doi.org/10.1177/08862609200 7003001

Simon, H. A. (1960). The New Science of Management Decision. New York: Harper and Row. http://dx.doi.org/10.1037/13978-000

Simon, H. A. (1973). Applying Information Technology To Organization Design. Public Administration Review, 33(3), 268. http://dx.doi.org/10.2307/974804

Strauss, A. (1987). Qualitative Analysis for Social Scientists. Retrieved from http://books.google.com.au/ books?id=y16ww5ZsJ0AC\&printsec $=$ frontcover\#v=onepage \&q \&f=false

Strauss, A., \& Corbin, J. (1998). Basics of Qualitative Research: Techniques and Procedures for Developing Grounded Theory (2nd ed.). Thousand Oaks, London, New Delhi: Sage Publications.

Taylor, S. J. B. R. (1984). Introduction to Qualitative Research Methods: The Search for Meanings (p. 310).

Tepper, B. J. (2000). Consequences of abusive supervision. Academy of Management Journal, 43(2), 178-190. http://dx.doi.org/10.2307/1556375

Tepper, B. J. (2007). Abusive supervision in work organizations: Review, synthesis, and research agenda. Journal of Management, 33(3), 261-289. http://dx.doi.org/10.1177/0149206307300812

Tepper, B. J., Carr, J. C., Breaux, D. M., Geider, S., Hu, C., \& Hua, W. (2009). Abusive supervision, intentions to quit, and employees' workplace deviance: A power/dependence analysis. Organizational Behavior and Human Decision Processes, 109(2), 156-167. http://dx.doi.org/10.1016/j.obhdp.2009.03.004 
Tepper, B. J., Duffy, M. K., \& Breaux-Siognet, D. M. (2012). Abusive supervision as political activity: Distinguishing impulsive and strategic expressions of downward hostility. In G. R. Ferris, \& D. C. Treadway (Eds.), Politics in organizations: Theory and research considerations. (pp. 191-212). New York, NY US: Routledge/Taylor \& Francis Group.

Tepper, B. J., Duffy, M. K., Henle, C. A., \& Lambert, L. S. (2006). Procedural injustice, victim precipitation, and abusive supervision. Personnel Psychology, 59(1), 101-123. http://dx.doi.org/10.1111/j.1744-6570. 2006.00725.x

Tepper, B. J., Duffy, M. K., Hoobler, J., \& Ensley, M. D. (2004). Moderators of the relationships between coworkers' organizational citizenship behavior and fellow employees' attitudes. The Journal Of Applied Psychology, 89(3), 455-465. http://dx.doi.org/10.1037/0021-9010.89.3.455

Tepper, B. J., Duffy, M. K., \& Shaw, J. D. (2001). Personality moderators of the relationship between abusive supervision and subordinates' resistance. The Journal Of Applied Psychology, 86(5), 974-983.

Tepper, B. J., Moss, S. E., \& Duffy, M. K. (2011). Predictors of abusive supervision: Supervisor perceptions of deep-level dissmiliarity, relationship conflict, and subordinate performance. Academy of Management Journal, 54(2), 279-294. http://dx.doi.org/10.5465/AMJ.2011.60263085

Tepper, B. J., Moss, S. E., Lockhart, D. E., \& Carr, J. C. (2007). Abusive supervision, upward maintenance communication, and subordinates' psychological distress. Academy of Management Journal, 50(5), 1169-1180. http://dx.doi.org/10.2307/20159918

Thau, S., Bennett, R. J., Mitchell, M. S., \& Marrs, M. B. (2009). How management style moderates the relationship between abusive supervision and workplace deviance: An uncertainty management theory perspective. Organizational Behavior and Human Decision Processes, 108(1), 79-92.

Weaks, D. (2002). Unlocking the secrets of 'good supervision': A phenomenological exploration of experienced counsellors' perceptions of good supervision. Counselling and Psychotherapy Research, 2(1), 33-39. http://dx.doi.org/10.1080/14733140212331384968

Willis, J. W. (2007). Foundations of Qualitative Research: Interpretive and Critical Approaches. Retrieved May 11, 2013, from http://www.amazon.com/Foundations-Qualitative-Research-Interpretive-Approaches/dp/ 1412927412\#reader_1412927412

Zellars, K. L., Tepper, B. J., \& Duffy, M. K. (2002). Abusive supervision and subordinates' organizational citizenship behavior. J Appl Psychol, 87(6), 1068-1076. http://dx.doi.org/10.1037/0021-9010.87.6.1068

\section{Copyrights}

Copyright for this article is retained by the author(s), with first publication rights granted to the journal.

This is an open-access article distributed under the terms and conditions of the Creative Commons Attribution license (http://creativecommons.org/licenses/by/3.0/). 